\title{
TRADUÇÃO/TRANSLATION
}

\section{SOBRE AS HIPÓTESES QUE SERVEM DE FUNDAMENTO À GEOMETRIA*}

\author{
Georg Friedrich RIEMANN (1826-1866)**

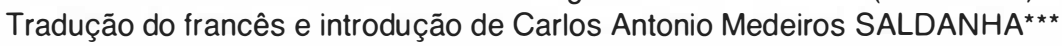

\section{NOTA INTRODUTÓRIA}

$\mathrm{Na}$ extensa bibliografia sobre a evolução do. pensamento científico, geralmente um capítulo especial é dedicado à exploração da seqüência de eventos que, a partır do século XVIII, culminaram com a apresentação da Teoria da Relatividade Especial e Geral, respectivamente, em 1905 e 1916, por Albert Einstein.

A Teơria da Relatividade Geral teve uma enorme repercussão na Ciência não só devido à sua maior beleza e elegância ao descrever os fenômenos gravitacionais, mas também porque deu um impulso novo e vigoroso à Cosmologia.

O modelo cosmológico newtoniano durante quase duzentos anos permanecera intocável. As concepções fundamentais de tempo e espaço absolutos eram consideradas inquestionáveis. E a lei da Gravitação de Isaac Newton respondia e maravilhava o espírto da época, ao explicar com tanta simplicidade a "Mecânica Celeste".

Com as Teorias da Relatividade Especial e Geral, dois gigantescos passos foram dados, trazendo, praticamente, uma nova visão da natureza. Com o primeiro passo, a Teoria Especial acaba com a separação do espaço e do tempo, como categorias distintas. Espaço e tempo são indissociáveis e formam o chamado "continuum" espacio-temporal, onde ocorrem os eventos do mundo. A Teoria Geral vai além. Adota o "continuum" espacio-temporal e associa a matéria à gravitação. Essa dupla associação traduz o fato de que o campo gravitacional determina as relações métricas do "continuum" espacio-temporal. Conclusão notável que modifica crenças arraigadas e coloca em cheque o senso comum.

Para essa conclusão genial de Albert. Einstein, muito contribuiu o trabalho de Georg Friedrich Bernhard Riemann (1826-1866) que, ao generalizar a teoria das superfícies curvas de Gauss

\footnotetext{
* Este memorial foi lido pelo autor em 10 de junho de 1854 por ocasião de suas provas de admissão à Faculdade de Filosofia de Göttingen. Assim se explica a forma de sua exposição, onde as pesquisas analíticas são somente indicadas.

** Sur les hypothèses que servent de fondement à la géométrie. Memoire de la Société Royale des Sciences de Göttingen, 1867. t. XIII, p. 272. In: Oeuvres Mathématiques de Riemann. Traduit par J. Hoüel. 2. ed. Paris, Librairie Scientifique Téchnique Albert Blanchard, 1968. p. 280-299.

*** Engenheiro Civil - HIDROSERVICE - Engenharia de Projetos Ltda. - 01000 - São Paulo - SP.
} 
a espaços " $n$ " dimensionais, teve, segundo as palavras do próprio Einstein, "a visão profétıca do significado físico dessa generalização da geometria Euclidiana".

A observação do fato de que os raios luminosos e os corpos livres se deslocam retilinearmente, quando referidos a um determinado sistema de referência, indicava para Riemann que o espaço não é amorfo. Ao contrário, deveria possuir uma estrutura própria, ou campo métrico, em analogia aos campos elétricos e magnéticos. Esse campo métrico, espalhando-se por todo o espaço, teria como causa física a matéria do Universo.

Essa foi a "visão profética" anunciada por Riemann em sua Aula Inaugural, em 10 de junho de 1854, na Universidade de Göttingen, ao apresentar a dissertação "Sobre as Hipóteses que Servem de Base à Geometria". Quando na dissertação examina a hipótese de Euclides, segundo a qual tanto as lınhas como os corpos têm uma existência independente da posição, está de fato lançando, indiretamente, as primeıras idéias de uma concepção inteiramente nova do espaço.

Talvez essa Aula Inaugural tenha sido o evento mais importante no desenvolvimento da Teoria Geral da Relatividade.

\section{PLANO DESTE ESTUDO}

Sabe-se que a geometria admite como dados prelimınares não somente o conceito do espaço, mas também as prımeiras idéias fundamentais das construções no espaço. Destes conceitos ela só dá defınıções nominais, as determinações essenciais introduzindo-se sob forma de axıomas. As relações mútuas destes dados primitıvos ficam envoltas em mistério, não se percebe bem se elas são obrigatoriamente ligadas entre si, nem até que ponto elas o são, nem mesmo "a priori" se elas o podem ser.

Desde Euclides até Legendre, para citar apenas o mais ilustre dos reformadores modernos da Geometria, ninguém, nem dentre os matemáticos, nem dentre os filósofos, conseguiu esclarecer este mistério. A razão disto é que o conceito geral das grandezas de dimensões múltiplas, compreendendo como caso particular as grandezas extensas, nunca foi objeto de qualquer estudo. Em conseqüência, coloquei-me primeiro o problema de construir, partindo do conceito geral de grandeza, o conceito de uma grandeza de múltiplas dimennsões. Parecerá desta forma que uma grandeza de múltiplas dimensões pode ter diferentes relações métricas e que o espaço é, por conseguinte, somente um caso particular de uma grandeza de três dimensões. Ora, decorre necessariamente deste fato que as proposições da Geometria não podem ser deduzidas dos conceitos gerais de grandeza, mas que as propriedades, pelas quais o espaço se distingue de qualquer outra grandeza imaginável de três dimensões, só podem ser tomadas da experiência. Daí o problema de se procurar (ou pesquisar) os fatos mais simples através dos quais se possam estabelecer as relações métricas do espaço, problema que, pela própria natureza do objeto, não está completamente determinado, pois podem-se indicar vários sistemas de fatos simples, suficientes para a determinação de relações métricas do espaço.

O mais importante, para nosso atual objetıvo, é aquele que Euclides tomou como base. Esses fatos, como todos os fatos possíveis, não são necessários. Só têm uma certeza empírica, são hipóteses. Pode-se, então, estudar sua probabilidade, que é certamente considerável nos limites de observação, e julgar, a partir disto, o grau de segurança de estender-se esses fatos fora desses limites, tanto no sentıdo dos imensuravelmente grandes quanto no dos imensuravelmente pequenos.

\section{A - Conceito de uma grandeza de $\boldsymbol{n}$ dimensões}

Tentando agora tratar do primeiro destes problemas, referente ao desenvolvimento do con- 
ceito de uma grandeza de dimensões múltiplas, eu me vejo na obrigação de pedir a indulgên-' dos leitores por não ser perito em trabalhos filosóficos desta natureza, cuja dificuldade se encontra mais na concepção do que na construção, e porque, com exceção de algumas breves indicações dadas pelo Sr. Gauss em seu segundo memorial sobre os resíduos biquadráticos, nos Gelehrte Anzeigen de Göttingen e em seu memorial de jubileu, e com excessão de algumas pesquisas filosóficas de Herbart, não pude me apoiar em nenhum trabalho anterior.

$\S$ I Os conceitos de grandeza só são possiveis desde que exista um conceito geral que permita diferentes modos de determinação. Segundo a possibilidade, ou não, de passar de um destes modos de determinação a um outro de maneira contínua, eles formam uma variedade contínua ou uma variedade discreta; no primeiro caso, o modo de determinação se chama ponto e no segundo, um elemento desta variedade. Os conceitos cujos modos de determinação formam uma variedade discreta são tão freqüentes que, dados objetos quaisquer, sempre existirá, pelo menos nas línguas cultas, um conceito que os compreenda (e os matemáticos estavam conseqüentemente no seu direito, na teoria das grandezas discretas, quando-tomavam como ponto de partida a condição de que os objetos dados sejam considerados da mesma espécie). Pelo contrário, as ocasiões que podem fazer nascer conceitos, cujos modos de determinação formam uma variedade contínua, são tão raras na vida comum que os locais dos objetos sensiveis e as cores são praticamente os únicos conceitos simples cujos modos de determinação formam uma variedade de várias dimensões. Somente nas altas matemáticas as ocasiões para a formação e o desenvolvimento destes conceitos se tornam mais freqüentes.

Uma parte de uma variedade, separada do resto por uma marca ou por um limite, é chamada quantum. A comparação dos quanta, do ponto de vista da quantidade, é feita, para as grandezas contínuas, por meio de medição. A medição consiste em superposição de grandezas a serem comparadas. É preciso, então, para medir, ter um meio de transportar a grandeza que serve de medida padrão (étalon) para as outras. Se faltar este meio, não será possível comparar duas grandezas entre si a menos que uma delas seja parte da outra, e neste caso só se poderá decidir a questão do maior ou do menor, e não a da relação numérica. As pesquisas que tal caso pode originar formam uma área geral da teoria das grandezas, independente de determinações métricas e na qual elas não são consideradas enquanto existentes independentemente da posição, nem expressáveis por meio de uma unidade, mas como regiões dentro de uma variedade. Tais pesquisas se tornaram necessárias em várias partes da matemática, notadamente para o estudo das funções analíticas com vários valores, e é principalmente devido às suas imperfeições que o célebre teorema de Abel, bem como os trabalhos de Lagrange, de Pfaff, de Jacobi, sobre a teoria geral das equações diferenciais, ficaram tanto tempo estéreis. Nesta área geral da teoria das grandezas, onde não se supõe nada mais do que já está incluído no conceito destas grandezas, nos bastará, para nosso atual objeto, estudar dois pontos que são correlatos: o primeiro, a geração do conceito de uma variedade de várias dimensões; o segundo, o meio de transformar as determınações de local de uma variedade dada, em determınações de quantidade, e é este último ponto que deve mostrar claramente o caráter essencial de um estudo de $n$ dimensões.

$\S$ II Dado um conceito cujos modos de determinação formam uma variedade contínua, se passarmos, segundo determinada maneira, de um modo de determinação a outro, os modos de determinação percorridos formarão uma variedade extensa num só sentido, cujo caráter essencial é que, nesta variedaḍe, só se pode, partindo de um ponto, avançar, de manerra contínua, em duas direções: para frente e para trás. Imaginemos, agora, que esta variedade seja transportada, por sua vez, sobre outra varıedade completamente distinta, isto também de uma 
maneira determinada, isto é, tanto que cada um de seus pontos se transporte para um ponto determinado de outra variedade; o conjunto dos modos de determinação assim obtidos formará uma variedade de duas dimensões. Obter-se-á de maneira semelhante uma variedade de três dimensões se se imaginar que uma variedade de duas dimensões se transporte de uma maneira determinada sobre outra completamente distinta; é fácil ver como se pode continuar esta construção. Se, em vez de considerar o conceito como determinável, considerarmos seu objetivo como variável, poderemos designar esta construção como a composição de uma variabilidade de $n$ dimensões.

$\S$ III Vou mostrar, agora, reciprocamente, como uma variabilidade, cujo campo é dado, pode ser decomposta em uma variabilidade de uma dimensão e uma variabilidade de um número de dimensões menores. Imaginemos, para isto, uma porção variável de uma variedade de uma dimensão, contada a partir de um ponto fixo, de modo que seus valores sejam comparáveis entre si; suponhamos que esta porção tenha, para cada ponto da variedade dada, um valor determinado, mudando com este ponto de um maneira contínua, ou, em outros termos, imaginemos, no interior da variedade dada, uma função contínua do local, função que não seja constante ao longo de uma porção desta variedade. Qualquer sistema de pontos, para o qual a função tem um valor constante, forma então uma variedade contínua de um número menor de dimensões que a variedade dada.

Estas variedades, quando fazemos variar a função, se transformam de maneira contínua umas nas outras; poderemos, então, admitir que uma dentre elas gera as outras, e ısto poderá acontecer, falando em geral, de tal modo que cada ponto de uma delas se transporte para um ponto determinado da outra. Os casos de exceção, cujo estudo é importante, podem aqui ser deixados de lado. Daí, a determinação de local numa variedade dada se resume a uma determinação de local numa variedade de menor número de dimensões. Ora, é fácil mostrar que esta última variedade tem $n-1$ dimensões quando a variedade dada tiver $n$. Repetındo $n$ vezes este processo, a determinação de local numa variedade de $n$ dimensões se resumırá a $n$ determınações de grandezas e assim a determinação de local em uma variedade dada, quando ısto for possivel, se reduz a um número finito de determinações de quantidade. Todavia, há também variedades nas quais a determinação de local exige não mais um número finito mas ou uma série infinita ou uma variedade contínua de determinações de grancieza.

Assım são, por exemplo, as variedades formadas pelas determinações possíveıs de uma função em uma região dada, pelas formas possíveis de uma figura do espaço, etc.

\section{B - Relações métricas das quais pode depender uma variedade de $\boldsymbol{n}$ dimensōes, na hipótese onde as linhas possuem um comprimento, independentemente de sua po- sição, e onde qualquer linha pode assim ser medida por qualquer outra linha.}

Após ter construído o conceito de uma variedade de $n$ dimensões e encontrado, como traço essencial desta variedade, esta propriedade que diz que a determinação de local, nela, pode ser resumida a $n$ determinações de grandeza, chegamos ao segundo problema exposto acima - saber do estudo das relações métricas, das quais tal variedade é suscetível, e das condições suficientes para a determinação destas relações métricas. Estas relações métricas só podem ser estudadas em conceitos abstratos de grandeza e sua dependência só pode ser representada por fórmulas. Entretanto, em certas hipóteses, elas podem ser decompostas em relações que, tomadas separadamente, podem ser representadas geometrıcamente, e, a partir daí, se torna possivel expressar, geometricamente, os resultados do cálculo. Assim, para se chegar a algo mais objetivo, não se pode, é verdade, evitar nas fórmulas as considerações 
abstratas, embora os resultados do cálculo possam ser em seguida representados sob forma geométrica. Os fundamentos destas duas partes da questão estão estabelecidos no famoso memorial do Sr. Gauss: Disquisitiones generales circa. superficies curvas.

$\S$ I As determinações métricas exigem a independência entre as grandezas e os locais, o que pode ser realizado de várias maneiras. A hipótese que aparece primeiro, e que desenvolverei aqui, é aquela em que o comprimento das linhas é independente de sua posição e, por conseguinte, cada linha pode ser medida por outra.

Sendo a determinação do local feita através das determinações de grandezas, e a posição de um ponto na variedade de $n$ dimensões sendo, por conseguinte, expressa por meio de $n$ grandezas $x_{1}, x_{2}, x_{3} \ldots, x_{n}$, a determinação de uma linha se resumirá ao fato das quantidades $x$ serem dadas como funções de uma variável. O problema consiste, então, em estabelecer uma expressão matemática do comprimento de uma linha, e, para isto, devem-se considerar as quantidades $x$ como expressáveis em unidades. Só tratarei este problema sob certas restrições, e me limitarei, em princípio, às linhas nas quais as relações entre os crescimentos dx das variáveis $x$ correspondentes variem de maneira contínua. Pode-se então conceber as linhas decompostas em elementos, na extensão dos quais as relações das quantidades $d x$ possam ser vistas como constantes, e o problema se resume, então, em estabelecer, para cada ponto, uma expressão geral do elemento linear ds partindo deste ponto, expressão esta que conterá assim as quantidades $x$ e as quantidades dx. Admitirei, em segundo lugar, que o comprimento do elemento linear, fazendo-se abstração das quantidades de segunda ordem, se mantém invariável quando todos os pontos deste elemento são submetidos a um deslocamento infinitamente pequeno, o que implica ao mesmo tempo que, se todas as quantidades dx crescerem numa mesma relação, o elemento linear variará igualmente nesta mesma relação. Estas hipóteses estando admitidas, o elemento linear poderá ser uma função homogênea qualquer de primeiro grau das quantidades $\mathrm{dx}$, que ficará invariável quando se mudarem os sinais de todas as quantidades $d x$, e na qual as constantes arbıtrárias serão funções contínuas das quantıdades $x$. Para encontrar os casos mais simples, procurarei, primeiro, uma expressão para as variedades de $n-1$ dimensões que sejam, em qualquer lugar, eqüidistantes da origem do elemento linear; ısto é, procurarei uma função contínua do local que as distinga umas das outras. Esta função deverá ou aumentar ou diminuir em todas as direções a partir da origem; admitirei que ela cresça em todas as direções e que, desta maneira, ela tenha um mínimo na origem. É preciso, então, se seus quocientes diferenciaıs de primeira e de segunda ordens forem finitos, que o diferencial de primeira ordem se anule e que o de segunda ordem jamais se torne negativo; admitirei que ele fica sempre positivo.

Esta expressão diferencial de segunda ordem fica, então, constante quando ds é constante, e cresce na relação dos quadrados quando as quantidades $d x$ e, por conseguinte, também as ds variam todas juntas numa mesma relação.

Então, esta expressão é = constante $\cdot d s^{2}$ e, por conseguinte, $d s=$ raiz quadrada de uma função inteira homogênea de segundo grau, sempre positiva, das quantidades $d x$, na qual os coeficientes são funções contínuas das quantidades $x$. Para o espaço, se expressamos a posição do ponto em coordenadas retangulares, obtemos: ds $=\sqrt{\Sigma}(\mathrm{dx})^{2}$; o espaço está, então, compreendido neste caso, o mais simples de todos. O caso mais simples, depois deste, compreenderia variedades das quais o elemento linear seria expresso pela raiz quarta de uma expressão diferencial de quarto grau. $O$ estudo desta classe mais geral não exigiria princípios essencialmente diferentes mas tomaria um tempo considerável e não contribuiria muito, relativamente, para esclarecer a teoria do espaço, inclusive porque os resultados não poderiam ser 
expressos geometricamente. Limitar-me-ei, então, às variedades nas quais o elemento linear é expresso pela raiz quadrada de uma expressão diferencial de segundo grau. Tal expressão pode ser transformada em outra semelhante, substituindo-se as $n$ variáveis independentes por funções de $n$ novas variáveis independentes. Mas não se poderá, através deste meio, transformar uma expressão qualquer em uma outra expressão qualquer, pois a expressão contém $n . \frac{n+1}{2}$ coeficientes, que são funções arbitrárias das variáveis independentes; ora, pela introdução de novas variáveis, só se poderá șatisfazer $n$ relações e, por conseguinte, só se poderá igualar $n$ coeficientes a quantidades dadas. Os $n . \frac{n-1}{2}$ coeficientes restantes serão então completamente determinados pela própria natureza da variedade que se trata de representar, e assim a determinação de suas relações métricas exige $n \cdot \frac{n-1}{2}$ funções do local. As variedades nas quais o elemento linear puder, como no plano e no espaço, se resumir à forma $\sqrt{\Sigma}(d x)^{2}$, formam, então, somente um caso particular das variedades que estudamos aqui; elas merecem um nome especial, e chamarei, por conseguinte, as variedades nas quais o quadrado do elemento linear puder se resumir a uma soma de quadrados diferenciais completos, variedades planas. Para poder, agora, examinar as diversidades essenciais de todas as variedades suscetíveis de serem representadas sob a forma considerada, é preciso deixar de lado as diversidades provenientes do modo de representação e isto se consegue com a escolha de grandezas variáveis segundo um princípio determinado.

§ II Para isto, imaginemos que, a partir de um ponto dado, tenhamos construído um sistema de linhas de menor distância que passem por este ponto; a posição de um ponto indeterminado poderá ser fixada através da direção inicial da linha de mais curta distância sobre a qual ele se encontre, e de sua distância contada sobre esta linha a partir da origem e, por conseguinte, ela poderá ser expressa através dos produtos $d x^{0}$ das quantidades $d x$ sobre esta linha de menor distância e através do comprimento $s$ desta linha. Introduzamos, agora, em vez de $d^{0}$, expressões lineares $\mathrm{d} \alpha$ formadas com estas quantidades e tais que o valor inicial do quadrado do elemento seja igual à soma dos quadrados destas expressões, de tal modo que as variáveis independentes sejam a grandeza $s$ e os produtos das quantidades da, e substituamos, finalmente, os $d \alpha$ pelas quantidades $x_{1}, x_{2}, \ldots x_{n}$, que lhes sejam proporcionais e cuja soma dos quadrados seja $=s^{2}$. Se introduzirmos estas grandezas, para valores infinitamente pequenos dos $\mathrm{x}$, o quadrado do elemento linear será $=\Sigma \mathrm{dx}^{2}$, o termo de ordem seguinte neste quadrado será igual a uma função homogênea de segundo grau das $n \cdot \frac{n-1}{2}$ grandezas $\left(x_{1} d x 2-\right.$ $\left.x_{2} d x_{1}\right),\left(x_{1} d x_{3}-x_{3} d x_{1}\right), \ldots$, isto é, ele será um infinitamente pequeno, de quarta ordem; de tal maneira que se obtém uma grandeza finita dividindo este termo pela soma dos quadrados dos lados do triângulo infinitamente pequeno cujos vértices correspondam aos sistema de valores $(0,0,0, \ldots),\left(x_{1}, x_{2}, x_{3}, \ldots\right),\left(d x_{1}, d x_{2}, d x_{3}, \ldots\right)$ das variáveis. Este termo conservará o mesmo valor, desde que as quantidades $\mathrm{x}$ e $\mathrm{dx}$ estejam contidas nas mesmas formas lineares binárias, ou enquanto as duas linhas de menor distância, desde os valores zero até os valores dx, ficarem no mesmo elemento superficial; e só depende, conseqüentemente, do local e da direção deste elemento. Este termo é evidentemente $=0$ quando a variedade representada for plana, isto é, quando o quadrado do elemento linear é redutível a $\Sigma \mathrm{dx}^{2}$, e pode, conseqüentemente, ser considerado como a medida da quantidade cuja variedade se afasta da planaridade* neste ponto e nesta direção superficial. Multiplicando-o por $-3 / 4$, ele se torna igual à quantidade que Gauss chamou medida de curvatura de uma superfície. Para determinar as relações métricas

\footnotetext{
* Ebenheit no original. (J. Hoüel)
} 
de uma variedade de $n$ dimensões, suscetível de uma representação sob a forma suposta, achamos, há pouco, que $\mathrm{n} . \frac{\mathrm{n}-1}{2}$ funções do local, são necessárias; se dermos, então em cada ponto, a medida da curvatura, segundo $n . \frac{n-1}{2}$ direções superficiais, poderemos determinar, através delas, as relações métricas da variedade, somente se entre estes valores não exıstirem relações idênticas, relações que geralmente não existem. As relações métricas destas variedades, onde o elemento linear é representado pela raiz quadrada de uma expressão diferencial de segundo grau, podem, desta forma, se expressar de um modo totalmente independente da escolha das grandezas variáveis. Pode-se, ainda, para este fim, seguir uma linha de ação totalmente semelhante no caso das variedades onde o elemento linear se expressa menos simplesmente, por exemplo, através da raiz quarta de uma expressão diferencial de quarto grau. Então, o elemento linear não seria mais, geralmente, redutível à forma de raiz quadrada de uma soma de quadrados de expressões diferenciais, e, por conseguinte, na expressão do quadrado do elemento linear, o afastamento da linearidade seria um infinitamente pequeno de segunda ordem, enquanto, nas variedades consideradas anteriormente, este afastamento era um infinitamente pequeno de quarta ordem. Esta propriedade, destas últimas variedades, pode ser chamada planaridade nas partes infinitesimais. Mas a propriedade mais importante destas variedades, para nosso objetivo atual, e a única que estudamos aqui, é aquela que consiste no fato das relações das variedades de duas dimensões poderem ser representadas geometricamente por superfícies, e as razões das variedades de maior númer de dimensões poderem ser resumidas às razões das superfícies que elas contêm. Todavia, isto exige uma curta explicação.

$\S$ III Na maneira de conceber aș superfícies, nas relações métricas intrínsecas, nas quais só se tem a considerar o comprimento dos caminhos traçados sobre estas superfícies, sempre se mistura a idéia de sua posição relativâmente aos pontos colocados fora delas. Mas pode-se fazer abstração das relações externas quando submetem-se estas superfícies a mudanças tais que o comprimento das linhas que nelas estão situadas fiquem invariáveis, isto é, quando as supomos flexíveis sem extensão, e quando consideramos como de mesma espécie todas as superfícies assim obtidas. Assim, por exemplo, superfícies cilíndricas ou cônicas quaisquer serão vistas como equivalentes a um plano, porque elas podem ser desenvolvidas sobre ele por simples flexão conservando-se invariáveis suas relações métricas intrínsecas e todas as proposições referentes a estas relações, isto é, continua a existir toda a planimetria. Elas são, ao contrário, essencialmente não equivalentes à esfera, que não pode ser desenvolvida em um plano. De acordo com a pesquisa anterior, as relações métricas intrínsecas, numa grandeza de duas dimensões, quando o elemento linear pode ser expresso pela raiz quadrada de uma expressão diferencial de segundo grau, como acontece nas superfícies, são caracterizadas em cada ponto pela medida da curvatura. Pode-se dar a esta quantidade, no caso das superfícies, uma interpretação sensível aos olhos, estabelecendo o produto das duas curvaturas das superfícies no ponto considerado, ou então, que seu produto pela soma dos ângulos internos de um triângulo infinitamente pequeno, formado de linhas de menor distância, é igual à metade do excesso da soma dos ângulos deste triângulo, em radianos, sobre dois ângulos retos. Pela primeira definição este teorema faria supor que o produto dos dois raios de curvatura fica invariável quando a superfície recebe uma simples flexão; pela segunda definição, ficaria suposto que para um mesmo local, o excesso da soma dos ângulos de um triângulo infinitamente pequeno sobre dois ângulos retos é proporcional à superfície do triângulo. Para dar uma representação que possa ser apreendida na medida de curvatura de uma variedade de $n$ dimensões de um ponto dado e seguindo uma direção superficial dada, passando por este ponto, deve-se partir do fato que uma linha de menor distância, partindo de um ponto, é completamente determinada quando é dada sua direção inicial.

Trans/Form/Ação, São Paulo, 11: 89-99, 1988. 
Partindo-se disso, obter-se-á uma superfície determinada prolongando-se linhas de menor distância, com direções iniciais partindo de um ponto dado e situadas sobre um elemento superficial dado, e esta superfície terá, no ponto dado, uma medida de curvatura determinada, que é ao mesmo tempo a medida de curvatura da variedade de $n$ dimensões no ponto dado e segundo a direção superficial dada.

§ IV Antes de passar às aplicações ao espaço, ainda é necessário apresentar algumas considerações sobre as variedades planas em geral, isto é, sobre as variedades nas quais o quadrado do elemento linear pode ser representado por uma soma dos quadrados de diferenciais exatas.

Numa variedade plana de $n$ dimensões, a curvatura em cada ponto e em cada direção é nula; ora, segundo a discussão precedente, basta saber, para determinar as relações métricas, que em cada ponto ela é nula segundo as $n \cdot \frac{n-1}{2}$ direções superficiais cujas curvaturas são independentes entre si.

As variedades cujas curvaturas são em qualquer lugar iguais a zero podem ser consideradas como caso particular das variedades cuja curvatura é constante em qualquer lugar. $O$ traço comum destas variedades cuja curvatura é constante é que as figuras podem se mover nelas sem aumentar sua extensão. Pois é evidente que nelas as figuras não poderiam ser submetidas a translações e rotações arbitrárias se a curvatura não fosse a mesma em cada ponto e em todas as direções. Mas, por outro lado, as relações métricas da variedade são completamente determinadas pela curvatura; então as relações métricas em volta de um ponto e em todas as direções são exatamente as mesmas que em volta de outro ponto, e por conseguinte pode-se, a partir deste ponto, exeçutar as mesmas construções, donde se conclui que, nas variedades em que a curvatura é constante, pode-se dar às figuras uma posição arbitrária qualquer. As relações métricas destas variedades dependem apenas do valor da curvatura e, quanto à representação analítica, podemos dar à expressão do elemento linear a forma $\frac{1}{1+\frac{\alpha}{4} \Sigma \mathrm{x}^{2}} \cdot \sqrt{\Sigma} \mathrm{d} \mathrm{x}^{2}$.

$\S \mathrm{V}$ Para esclarecer por um exemplo geométrico o que foi dito antes, consideremos as superiícies de curvatura constante. É fácil ver que as superfícies cujas curvaturas sejam constantes e positivas podem sempre ser aplicadas sobre uma esfera cujo raio é igual à unidade dividida pela raiz quadrada da curvatura, mas, para visualizar de uma só vez a variedade inteira destas superfícies, vamos dar a uma delas a forma de uma esfera e às outras a forma de superfícies de revolução, tangenciando-as segundo o equador.

As superfícies de maior curvatura que esta esfera tocarão então a esfera interiormente e tomarão uma forma semelhante à parte exterior de uma superfície anelar, e mais afastada do eixo desta superfície. Elas seriam aplicáveis sobre zonas de esferas de raio menor, mas cobririam estas zonas mais de uma vez. As superfícies de menor curvatura positiva serão obtidas recortando, sobre superfícies esféricas de maior raio, um fuso limitado por dois grandes semicírculos, e unindo entre si as linhas de intersecção.

A superfície de curvatura nula será uma superfície cilíndrica tendo por base o equador; as superfícies de curvatura negativa tocarão este cilindro exteriormente e terão uma forma semeIhante à da parte interna de uma superfície anelar, virada para o eixo.

Se considerarmos estas superfícies como o local onde pode se mover um elemento de superfície, assim como o espaço é o local onde se movem os corpos, o elemento de superfície se moverá sobre todas estas superfícies sem sofrer ampliações. As superfícies de curvatura posi-

Trans/Form/Ação, São Paulo, 11: 89-99, 1988. 
tıva poderão sempre receber uma forma tal que os elementos de superfície possam também se mover nelas sem flexão, e esta forma será a de uma esfera; mas isto não é mais possível no caso da curvatura negativa. Além desta propriedade dos elementos de superfície serem independentes do local, a superfície de curvatura nula possui também a propriedade da dıreção ser independente do local, propriedade esta que não existe nas outras superfícies.

\section{C - Aplicação ao espaço}

$\S$ । Após este estudo sobre a determinação das relações métrıcas de uma grandeza de $n$ dimensōes, pode-se agora indicar as condições necessárias e suficientes para a determinação das relações métricas do espaço, quando admitimos como hipótese que as linhas são independentes de sua posição e que o. elemento linear pode ser expresso pela raiz quadrada de uma expressão diferencial de segundo grau, isto é, que o espaço é uma grandeza plana nas suas partes infinitesimais.

Elas podem primeiro se expressar desde que a medida de curvatura em cada ponto seja nula segundo três direções superficiais, e, por conseguinte, as relações métricas do espaço serão determinadas se a soma dos ângulos de um triângulo for em toda a parte igual a dois retos.

Se supusermos, em segundo lugar, como Euclides, uma existência independente da posição, não somente para as linhas mas também para os corpos, segue-se que a curvatura será sempre constante e então a soma dos ângulos será determinada, em todos os triângulos, quando ela o for em um só.

Finalmente, poderíamos ainda, em terceiro lugar, em vez de admitir que o comprimento das linhas é independente do local e da direção, supor que seu comprimento e sua direção são independentes do local. Segundo este ponto de vista, as mudanças de local ou as diferenças de local são grandezas complexas, expressáveis por meio de três unidades independentes.

$\S$ H No decorrer das considerações que acabamos de apresentar, separamos primeiro as relações de extensão ou de região das relações métricas, e achamos que, para as mesmas relações de extensão, poderíamos conceber diferentes relações métricas; procuramos em seguida os sistemas de determinações métricas simples, por meio dos quais as relações métricas do espaço são completamente determinadas e em que todas as proposições referentes a estas relações são conseqüências necessárias. Resta-nos agora examinar como, em que grau e com qual extensão estas hipóteses são confirmadas pela experiência. Sob este ponto de vista existe, entre as simples relações de extensão e as relações métricas, esta diferença essencial que, nas primeiras, onde os casos possíveis formam uma variedade discreta, os resultados da experiência nunca são completamente certos mas não são inexatos, enquanto que, na segunda, onde os casos possiveis formam uma variedade contínua, qualquer determ!nação da experiência é sempre inexata, não importando quão grande possa ser a probabilidade de sua exatidão aproximada. Esta cırcunstância torna-se importante quando se trata de estender estas determınações empíricas além dos limites da observação, no imensuravelmente grande ou no imensuravelmente pequeno, pois as segundas relações podem evidentemente se tornar cada vez mais inexatas assim que se sai dos limites da observação, enquanto não acontece o mesmo com as primeiras.

Quando se estendem as construções do espaço ao imensuravelmente grande, deve-se fazer a distinção entre o ilimitado e o infinito; o primeiro pertence às relações de extensão, o segundo às relações métricas. Que o espaço seja uma variedade ilimitada de três dimensões é uma hipótese que se aplica em todas as nossas concepções do mundo exterior, que nos serve para completar a cada instante o domínio de nossas percepções efetivas e construir locais

Trans/Form/Ação, São Paulo, 11: 89-99, 1988. 
possiveis de um objeto procurado, e que se encontra constantemente verificada em todas as suas aplicações. A propriedade do espaço ser ilimitado possui então uma maior certeza empírica que qualquer outro dado externo da experiência. Mas a infinidade do espaço não é de maneira alguma conseqüência disto; pelo contrário, se supusermos os corpos independentes do local e ainda atribuírmos ao espaço uma medida de curvatura constante, o espaço seria necessariamente finito sempre que a curvatura fosse positiva, por menor que fosse. Prolongando, seguindo linhas de menor distância, as direções ınıcıais situadas num elemento de superfície, obter-se-ia uma superfície ilimitada de curvatura constante, isto é, uma superfície que, em uma variedade plana de três dimensões, tomaria forma de uma superfície esférica, e que seria por conseguinte finita.

§ III As questões sobre o imensuravelmente grande são questões inúteis para a explıcação da natureza. Mas a coisa é diferente quando se trata de questões sobre o imensuravelmente pequeno. É sobre a exatidão com a qual acompanhamos os fenômenos no infinitamente pequeno que se baseia essencialmente nosso conhecimento de suas relações de causalidade. Os progressos dos últimos séculos no conhecimento da natureza mecânica dependem quase unicamente da exatidão da construção que se tornou possível graças à invenção da análıse do infinito e aos princípios simples descobertos por Arquimedes, por Galileu e por Newton e dos quais se utıliza a física moderna. Mas nas Ciências Naturaıs, onde os princípios simples ainda faltam para tais construções, procura-se reconhecer a relação de causalidade seguindo os fenômenos de extensão muito pequena, tão longe quanto o permita o microscópio. As questōes sobre as relações métricas do espaço no ımensuravelmente pequeno não são então questões supérfluas.

Se supusermos que os corpos existem independentemente do local, a medida de curvatura é, em qualquer lugar, constante e resulta então, das medidas astronômicas, que ela não pode ser diferente de zero; em todos os casos seria necessário que seu valor recíproco (raio) fosse uma grandeza em presença da qual o alcance de nossos telescópıos fosse como que nulo. Mas se esta independência entre os corpos e o local não existe, e sendo então reconhecidas relações métricas no infinitamente grande, não se pode concluır nada para as relações métricas do infinitamente pequeno; então a curvatura de cada ponto pode ter, segundo três direções, um valor arbitrário, na condição de que a curvatura total de qualquer porção mensurável do espaço não seja sensivelmente diferente de zero; podem ser introduzidas relações ainda mais complicadas, quando não se supõe mais, que o elemento linear possa ser representado pela raiz quadrada de uma expressão diferencial de segundo grau. Ora, parece que os conceitos empíricos sobre os quais são fundamentadas as determinações métricas da extensão, o conceito de corpo sólido e do raio luminoso param de existir no infinitamente pequeno.

É então perfeitamente legítimo supor que as relações métricas do espaço no infinitamente pequeno não são conformes às hipóteses da geometria, e é o que se deveria efetıvamente admitir, a partir do momento em que se obteria daí uma explicação mais simples dos fenômenos.

A questão da validade das hipóteses da geometria no infinitamente pequeno está ligada à questão do princípio íntimo das relações métricas do espaço. Nesta última questão, que podemos ainda ver como pertencente à doutrina do espaço, achamos a aplicação do comentário precedente que, numa variedade discreta, o princípio das relações métricas já está contido no conceito desta variedade enquanto que, numa variedade contínua, este princípio deve vir de outro lugar. É preciso, então, ou que a realıdade sobre a qual é fundado o espaço forme uma variedade discreta ou que o fundamento das relações métricas seja procurado fora dele, nas forças de ligação que agem sobre ele. 
A resposta a estas questões só pode ser obtida partindo-se da concepção dos fenômenos, verificada até então pela experiência, e que Newton tomou por base, e trazendo a esta concepção as modificações sucessivas exigidas pelos fatos que ela não pode explicar. Pesquisas partindo de conceitos gerais, como o estudo que acabamos de fazer, não podem ter outra utilidade que aquela de impedir que este trabalho seja prejudicado por visões muito estreitas, e que o progresso no conhecimento da dependência mútua das coisas não encontre um obstáculo nos preconceitos tradicionais.

Isto nos leva ao campo de uma outra ciência, ao campo da Física que foge do objetivo deste trabalho. 